\title{
Comparative genomic analysis of Geobacter sulfurreducens KN400, a strain with enhanced capacity for extracellular electron transfer and electricity production
}

\author{
Jessica E Butler ${ }^{*}$, Nelson D Young, Muktak Aklujkar and Derek R Lovley
}

\begin{abstract}
Background: A new strain of Geobacter sulfurreducens, strain KN400, produces more electrical current in microbial fuel cells and reduces insoluble Fe(III) oxides much faster than the wildtype strain, PCA. The genome of KN400 was compared to wildtype with the goal of discovering how the network for extracellular electron transfer has changed and how these two strains evolved.

Results: Both genomes were re-annotated, resulting in 14 fewer genes (net) in the PCA genome; 28 fewer (net) in the KN400 genome; and ca. 400 gene start and stop sites moved. 96\% of genes in KN400 had clear orthologs with conserved synteny in PCA. Most of the remaining genes were in regions of genomic mobility and were strain-specific or conserved in other Geobacteraceae, indicating that the changes occurred post-divergence. There were 27,270 single nucleotide polymorphisms (SNP) between the genomes. There was significant enrichment for SNP locations in non-coding or synonymous amino acid sites, indicating significant selective pressure since the divergence. 25\% of orthologs had sequence differences, and this set was enriched in phosphorylation and ATP-dependent enzymes. Substantial sequence differences (at least 12 non-synonymous SNP/kb) were found in $3.6 \%$ of the orthologs, and this set was enriched in cytochromes and integral membrane proteins. Genes known to be involved in electron transport, those used in the metabolic cell model, and those that exhibit changes in expression during growth in microbial fuel cells were examined in detail.
\end{abstract}

Conclusions: The improvement in external electron transfer in the KN400 strain does not appear to be due to novel gene acquisition, but rather to changes in the common metabolic network. The increase in electron transfer rate and yield in KN400 may be due to changes in carbon flux towards oxidation pathways and to changes in ATP metabolism, both of which indicate that the overall energy state of the cell may be different. The electrically conductive pili appear to be unchanged, but cytochrome folding, localization, and redox potentials may all be affected, which would alter the electrical connection between the cell and the substrate.

Keywords: Geobacter sulfurreducens KN400, Comparative genomics, Microbial fuel cell, Extracellular electron transfer

\footnotetext{
* Correspondence: jbutler@microbio.umass.edu

Department of Microbiology, 203 Morrill Science Center IVN, University of

Massachusetts, 639 North Pleasant Street, Amherst, MA 01003, USA
} 


\section{Background}

The ability to effectively transfer electrons directly onto insoluble, extracellular substances is one of the hallmark characteristics of Geobacter species. In the natural environment, Geobacter species are commonly the most abundant microorganisms in anaerobic soils and sediments where microbial reduction of insoluble Fe(III) oxides is important [1]. In addition, Geobacter species can be used to make microbial fuel cells - devices in which electrical current is harvested from bacteria that grow by transferring electrons from their food source to the anode of the device [1-3]. Pure cultures of Geobacter sulfurreducens produce current densities that are among the highest known [4], and G. sulfurreducens has been enriched from a number of complex communities growing in biofilms on high-efficiency microbial fuel cells [3]. However, the mechanisms for extracellular electron transfer in Geobacter species are poorly understood [1].

Recently, a new strain of G. sulfurreducens, designated strain KN400, was isolated that is much more effective than wildtype both in electron transfer to electrodes [5] and in Fe(III) oxide reduction (KA Flanagan, personal communication). Strain KN400 was isolated from a culture that grew by transferring electrons to an anode poised at a very low potential (-200 $\mathrm{mV} \mathrm{SHE})$ [5]. Compared to the wildtype strain, when growing in microbial fuel cells KN400 forms biofilms on the anode more rapidly; it produces much higher-density current (7.4 versus $1.4 \mathrm{~A} / \mathrm{m}^{2}$ ) and power (3.9 versus $0.5 \mathrm{~W} / \mathrm{m}^{2}$ ) [5]; and it has higher conductivity (350 versus $75 \mu \mathrm{S} / \mathrm{cm}$ ) [6].

Because it was recently isolated, little is known about how KN400 differs from the wildtype strain. Here we present the analysis of the genome of KN400 [7] and compare it to the genome of wildtype G. sulfurreducens PCA [8] in order to provide insight into both the phenotype of enhanced extracellular electron transfer and the evolutionary history of the species. We identify the genes that are unique to each strain and identify polymorphisms between the genomes. We analyze functional enrichment in the set of genes with sequence changes, and focus on differences in genes involved in electron transfer pathways from intracellular oxidation to electron transfer onto extracellular acceptors. We use these analyses to suggest how the metabolic network of the species has evolved and how these differences caused the divergent phenotypes.

\section{Results and discussion}

\section{Reannotation of the G. sulfurreducens strains KN400 and} PCA genomes

As published, the G. sulfurreducens strain PCA genome was $3.8 \mathrm{Mb}$ with 3466 open reading frames (ORFs) [8] and the G. sulfurreducens strain KN400 genome was $3.7 \mathrm{Mb}$ with 3356 ORFs [7]. Because the two genomes were sequenced and annotated several years apart using different methods, we re-annotated both genomes, making several types of corrections in order to assure that comparisons between the two were valid. ORF predictions, start and stop sites of the genes, and functional predictions were compared and reconciled using identical methods on both genomes (Additional file 1: Table S1 and Additional file 1: Table S2).

After the re-annotations, the strain KN400 genome had 3328 ORFs (Additional file 1: Table S1), and the strain PCA genome had 3432 ORFs (Additional file 1: Table S2). These re-annotations were deposited in the National Center for Biotechnology Information genome database under the accession numbers of AE017180.2 for PCA and NC_017454 for KN400. A summary of the basic characteristics of the genomes is given in Table 1 .

Whole-genome comparison of strain KN400 to strain PCA Orthologs, proteins predicted to have the same function in both genomes, were identified using a combination of whole-genome alignment and all-versus-all protein sequence alignments. A whole-genome nucleotide alignment of the PCA and KN400 genomes showed that they were syntenic, with no large-scale rearrangements or inversions (Additional file 2: Figure S1). Orthologs were identified for 3180 of the 3328 protein-coding genes in the KN400 genome (Additional file 1: Table S1). A whole-proteome comparison identified orthologs for 3194 genes (Additional file 1: Table S1). The two methods agreed for 3166 (99.6\%) of the pairs, with the genome method identifying 14 orthologs with identical sequences: eight transposases, two cytochromes, and a translation elongation factor, as well as three orthologs under 100 amino acids in length (Additional file 1: Table S1).The proteome method identified 28 orthologs with low sequence similarity or alignment over a short region of the sequence (Additional file 1: Table S1). For the analysis of polymorphisms between orthologs presented below, we included orthologs identified by only one method if they aligned over at least $50 \%$ of the length of the longer protein, and had a sequence identity of at least $30 \%$.

In total, 3192 of the 3328 ORFs in the KN400 strain genome (96\%) have orthologs in the PCA strain genome

Table 1 Characteristics of the re-annotated G. sulfurreducens genomes

\begin{tabular}{lll}
\hline & strain KN400 & strain PCA \\
\hline genome size (bp) & 3714272 & 3814128 \\
open reading frames & 3328 & 3432 \\
G + C content (\%) & 61.3 & 60.94 \\
rRNA operons & 2 & 2 \\
plasmids & 0 & 0 \\
\hline
\end{tabular}


(Additional file 1: Table S1 and Additional file 1: Table $\mathrm{S} 2$ ). The relative locations of the conserved genes are largely preserved between the genomes (Additional file 2: Figure S1).

\section{Genes unique to the KN400 strain}

There were no orthologs in the PCA strain for 126 of the ORFs (3.8\%) in the KN400 strain genome (Figure 1, Additional file 1: Table S3). In order to better to describe these genes and their evolutionary history, their locations and characteristics were mapped and their sequences were compared to proteins from the 10,291 organisms in the Reference Sequence database from the National Center for Biotechnology Information [9].

Seventeen of these 126 ORFs had no significant similarity to any gene in another organism, six were most similar to proteins in the PCA strain, and 37 had highest similarity to proteins in Geobacteraceae species other than PCA (Additional file 1: Table S3). The remaining
ORFs were most similar to genes from a variety of phylogenetically diverse organisms including Desulfovibrio, Syntrophobacter, Pseudomonas, and Vibrio species (Additional file 1: Table S3), suggesting that there are diverse evolutionary histories for these genes.

The 126 genes are spread throughout the KN400 genome, the majority in clusters together (Additional file 2: Figure S1). In total, there are 18 regions in the KN400 genome where at least two consecutive genes have no ortholog in the PCA genome (Additional file 1: Table S4). Eight are bordered by or contain transposase or integrase genes, three are bordered by tRNA genes, and one is bordered by a conserved repeated nucleic acid sequence (Additional file 1: Table S4) - indicating that these regions may be or once were mobile genetic elements [10].

One strain-specific region, found at 466250-483475 in the KN400 genome (genes KN400_0440-KN400_0451), is inserted relative to PCA just downstream of a tRNA

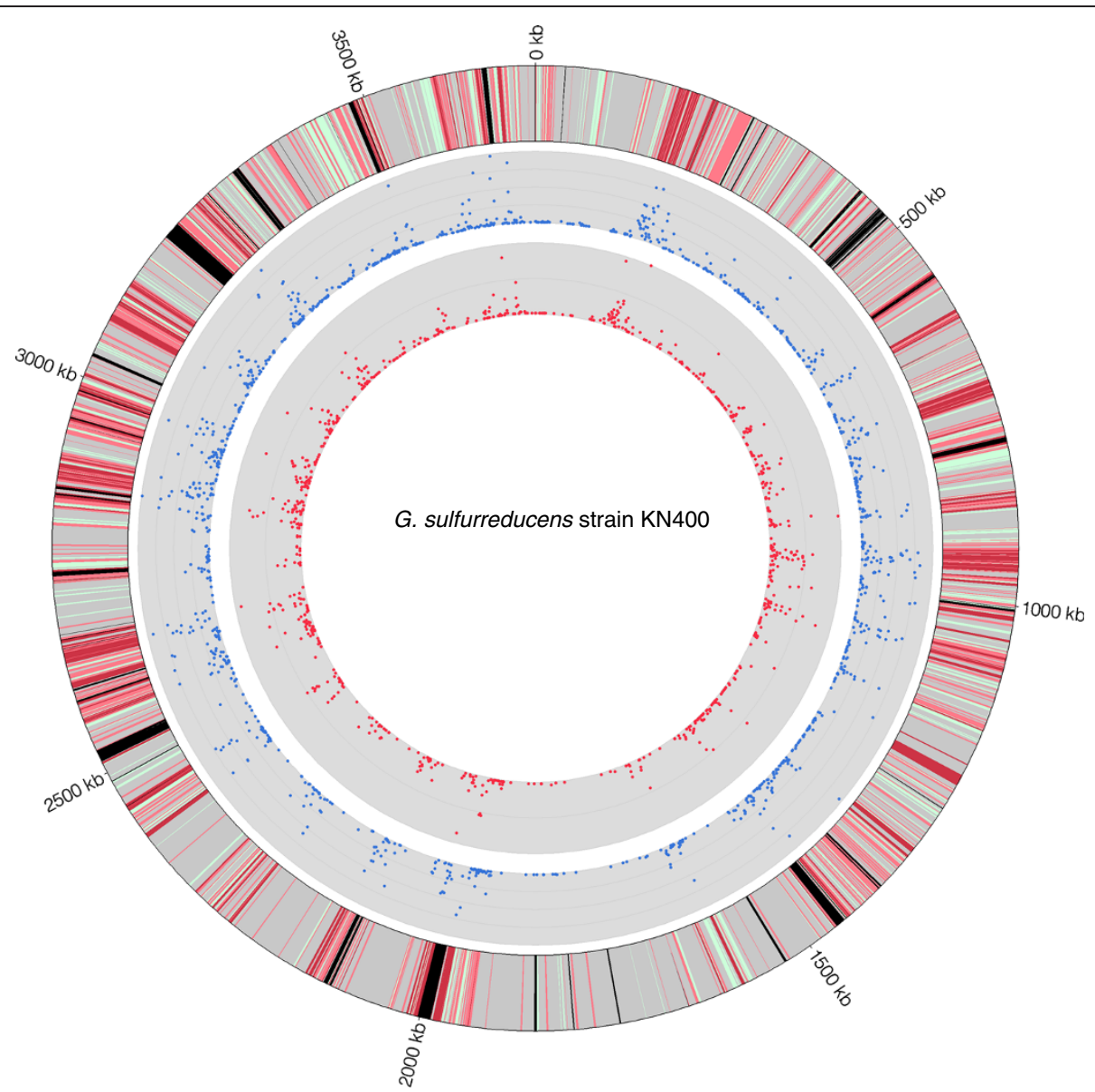

Figure 1 G. sulfurreducens strain KN400 genome differences compared to strain PCA. Inner ring: the number of non-synonymous (those that affect protein sequence) single nucleotide polymorphisms (SNP) per gene. Line scale $=25$ SNP Center ring: the total number of SNP per gene. Line scale $=25$ SNP. Outer ring: Gene-scale differences in orthologs. Genes with only silent mutations are green, those that have less than 12 non-synonymous SNP per kb (within two standard deviations of the mean) are light red, and those with at least 12 non-synonymous SNP are dark red. Identical genes are grey. Those genes that lack orthologs entirely are black. 
gene, between the orthologs to GSU0465 and GSU0466 (Additional file 1: Table S1). This region encodes a phage integrase and replisome organizer as well as a restriction/ modification system. The two genes for the restriction/ modification system (KN400_0449 and KN400_0451) are similar to genes from Meiothermus ruber, and are not found in any other Geobacteraceae, suggesting that this region may have been acquired by lateral gene transfer.

Another KN400 strain-specific region is found between 3479100-3485200. Here, KN400_3199-KN400_3206 are found between the orthologs to GSU3265 and GSU3267 (Additional file 1: Table S1). The genes include five conserved hypothetical proteins and three proteins involved in metal transport and usage: a metal-transporting ATPase, a metal-dependent phosphohydrolase, and a hybrid iron transport/cell signaling protein. All of these genes are most similar to those found in other Geobacteraceae and Deltaproteobacteria (Additional file 1: Table $\mathrm{S} 1$ ), suggesting that they might have been lost in the PCA strain genome.

In addition to regions of relative insertion in KN400, there are others where, between regions of excellent conservation between the two genomes, there is a stretch of sequence for which there is little or no similarity. For example, KN400_1871 and GSU1849 are orthologs, and KN400_1883 and GSU1857 are orthologs, but the region between them has low sequence similarity (Additional file 2: Figure S2, Additional file 1: Table S1). However, in both strains, the genes encode products involved in exopolysaccharide biosynthesis (Additional file 1: Table S1; Additional file 1: Table S2). This may be a region where mutation accumulation was relatively unconstrained, and these genes are attractive targets for studies of differences in the biofilms formed by strains PCA and KN400.

A few of the genes found in the KN400 genome but not the PCA genome are isolated, not in the 18 clusters described above. One of these that may have a substantial effect on metabolism is the catalase. The KN400_2748 gene encodes a KatE catalase [11], while the catalase of G. sulfurreducens strain PCA, GSU2100, encodes a KatGtype [11] of no sequence similarity. While each strain encodes only one of the two catalases, there is evidence that each once encoded the other. KN400 has a region with nucleic acid similarity to the katG gene (2278624$2280808 \mathrm{KN} 400$ ), but a single-base deletion results in a frameshift halfway through it. In the PCA genome, the region 3089478-3089600 aligns with the 5' end and the 3' end of the katE gene in KN400, though 90\% of the gene has been deleted. Both KatE and KatG detoxify reactive oxygen species, but their mechanism and expression are different [11]. Response to oxidative stress is especially important in Fe(III)-reducing, obligate anaerobes like Geobacter sulfurreducens - reactive oxygen species cause
DNA damage and disable many respiratory enzymes, and the presence of ferrous iron can create more of these compounds [12]. A difference in response to oxidative stress between the strains could affect many aspects of growth.

\section{Genes unique to the PCA strain}

249 ORFs in the PCA genome (7.2\%) did not have orthologs in the KN400 genome (Additional file 1: Table S5). Gene ontology analysis showed that three types of genes were very highly enriched in this group relative to the whole genome: those involved in DNA transposition, DNA integration, and RNA-dependent DNA replication (Additional file 1: Table S6). As with strain KN400, these ORFs were mostly found in clusters within the PCA genome (Additional file 2: Figure S1). There are 18 regions in the PCA genome in which at least two consecutive genes have no orthologs in the KN400 genome, (Additional file 1: Table S7). Twelve of these are bordered by (or contain) transposases, three by a tRNA gene(s), and two by conserved nucleic acid sequences. Compared to the KN400 strain, there are more transposases and more diverse types of transposases associated with these regions.

Several of these non-orthologous regions in the PCA genome are much larger than any of those found in the KN400 genome (Additional file 2: Figure S1). In the KN400 genome, 4 of the non-orthologous regions have at least ten genes, and the largest has 22 genes. In the PCA genome, 10 regions have at least ten genes, and the largest has 89 genes (Additional file 1: Table S4 and Additional file 1: Table S7).

The largest region of non-orthology to KN400 is between 2316300-2393600 in the PCA genome (Additional file 1: Table S7). This region of 89 ORFs (GSU2105GSU2183) is inserted relative to the KN400 genome between KN400_3465 and a tRNA gene at 2285100. Twothirds of the proteins encoded in this region are proteins of unknown function or transposases. Other proteins encoded include five putative transcriptional regulators and two efflux pumps (Additional file 1: Table S5). The second largest region unique to the PCA genome is between 49500-81300 (Additional file 1: Table S7). This region of 26 ORFs (GSU3471-GSU0064) is inserted relative to strain KN400 between a tRNA gene and KN400_0040. The majority of the proteins encoded here are also transposases and proteins of unknown function. However, this region also encompasses the CRISPR1 locus, six CRISPRassociated genes and a toxin/antitoxin pair, genes involved in resistance to exogenous DNA and potentially in gene regulation $[13,14]$.

In total, the KN400 genome is ca. $100 \mathrm{~kb}$ smaller than the PCA genome, with the difference due to the ca. 100 genes in KN400 with no ortholog in PCA and ca. 200 
genes in PCA with no ortholog in KN400. These genes have a variety of different apparent histories - some are not found in any other organism, some are syntenic between the genomes but lack sequence homology, some appear to have been lost entirely in one of the strains, and some may have arisen from lateral gene transfer from unrelated species. Strain-specific genes of potential interest include a number for membrane transport and polysaccharide metabolism; a restriction/modification system; catalases; a disulfide bond formation operon unique to KN400; and a CRISPR locus unique to PCA. The evolutionary history of the mobile genetic elements that are enriched in these regions also warrants further investigation.

\section{Single nucleotide polymorphisms (SNP) between the PCA and KN400 genomes}

Using an alignment of the two whole genomes, 27,270 single nucleotide polymorphism sites and small insertions or deletions between the two strains were identified (Figure 1, Additional file 1: Table S8). Of these, 23,773 (87\%) were intragenic in the PCA strain, with a rate of $6.8 \mathrm{SNP} / \mathrm{kb}$ in coding regions and $10.5 \mathrm{SNP} / \mathrm{kb}$ in non-coding regions.

Within the 3192 genes that had orthologs in both genomes, there were 17,964 SNP and 182 small-scale insertions or deletions (Figure 1, Table 2). The large majority (72\%) of the sequence differences between the KN400 and the PCA orthologs were silent, meaning that the SNP caused no changes to translation, and that the protein sequences of the orthologs were identical. The remaining 5109 SNP (28\%) were non-synonymous they caused a difference in amino acid sequence during translation (Figure 1, Table 2).

One-third of genes had a change of sequence between the strains - 1160 of the 3192 orthologs had at least one SNP, with an average of 5.6 per gene (15.5 per gene in genes that had at least one SNP) (Figure 1, Table 2). A rate of $34 \mathrm{SNP} / \mathrm{kb}$ was two standard deviations above average.

One-quarter of proteins had a change of sequence between the strains - 786 of the 3192 orthologs had at least one non-synonymous SNP, with an average of 1.6 per ortholog (4.4 per gene with at least one SNP) (Figure 1, Table 2). The set of genes that had at least one non-synonymous SNP was significantly enriched in genes for: $c$-type cytochromes, integral membrane proteins, phosphorus and phosphate metabolism, cofactor biosynthesis, and ATP-dependent enzymes with a wide variety of functions including: transporters and exporters, helicases, mismatch repair proteins, excinucleases, proteases, and many sensor histidine kinases (Additional file 1: Table S6).

Proteins were considered heavily mutated if the corresponding gene had at least 12 non-synonymous SNP/kb, which was two standard deviations above average (Table 2). 125 of the orthologs (3.6\%) were heavily mutated (Table 3, Additional file 1: Table S9). The set of heavily mutated proteins was significantly enriched in $c$ type cytochromes and in membrane-bound transport proteins (Table 3, Additional file 1: Table S6).

Some genes had only silent SNP, or sequence changes that did not affect the resulting protein sequence, indicating that changes to their sequence may be under negative selective pressure. Solely silent changes were present in 373 of the orthologs (12\%) (Additional file 1: Table S1). This set of genes was significantly enriched in genes involved in flagellum biogenesis and amino acid biosynthesis (Additional file 1: Table S6). The KN400 strain, unlike the PCA strain, produces flagella and is motile [5]. The most notable silent-mutation-rich region of the genome was cluster GSU1095-GSU1102, which encodes a phosphate transporter and phosphatedependent regulatory genes (Additional file 1: Table S2).

In order to better understand the phenotypic effects of the nucleotide polymorphisms between the strains, several metabolic networks involved in electron transfer out of the cell were examined in more detail.

\section{Sequence differences in central energy metabolism}

G. sulfurreducens primarily grows by coupling the oxidation of acetate to the reduction of extracellular electron acceptors. Acetate is oxidized by the TCA cycle, with the products used to generate a proton gradient for ATP

Table 2 Summary of the number and types of SNP in different classes of genes

\begin{tabular}{|c|c|c|c|c|c|c|c|c|c|c|c|c|c|c|c|c|}
\hline PCA & Total & $\begin{array}{l}\text { KN400 } \\
\text { orthologs }\end{array}$ & $\begin{array}{l}\text { \% with } \\
\text { orthologs }\end{array}$ & $\begin{array}{l}\text { Total } \\
\text { SNP }\end{array}$ & $\begin{array}{l}\text { Total } \\
\text { NS } \\
\text { SNP }\end{array}$ & $\begin{array}{l}\% \text { NS } \\
\text { SNP }\end{array}$ & $\begin{array}{l}\text { genes } \\
\text { with } \\
\text { SNP }\end{array}$ & $\begin{array}{l}\text { \% Genes } \\
\text { w.SNP }\end{array}$ & $\begin{array}{l}\text { Genes } \\
\text { with } \\
\text { NS } \\
\text { SNP }\end{array}$ & $\begin{array}{l}\text { \% genes } \\
\text { w.NS } \\
\text { SNP }\end{array}$ & $\begin{array}{l}\text { SNP/ } \\
\text { gene }\end{array}$ & $\begin{array}{l}\text { NS } \\
\text { SNP/ } \\
\text { gene }\end{array}$ & $\begin{array}{l}\text { SNP/ } \\
\text { SNPed } \\
\text { gene }\end{array}$ & $\begin{array}{l}\text { NS } \\
\text { SNP/ } \\
\text { SNPed } \\
\text { gene }\end{array}$ & $\begin{array}{l}\text { \# genes } \\
\geq 1.2 \% \\
\text { NS } \\
\text { SNP }\end{array}$ & $\begin{array}{l}\% \text { genes } \\
\geq 1.2 \% \\
\text { NS } \\
\text { SNP }\end{array}$ \\
\hline genes & 3432 & 3192 & 92.6 & 18146 & 5109 & 28.2 & 1160 & 36.3 & 786 & 24.6 & 5.6 & 1.6 & 15.5 & 4.4 & 114 & 3.6 \\
\hline $\begin{array}{l}\text { central } \\
\text { metabolism }\end{array}$ & 85 & 85 & 100.0 & 180 & 37 & 20.6 & 34 & 40.0 & 17 & 20.0 & 2.1 & 0.4 & 5.3 & 1.1 & 1 & 1.2 \\
\hline cytochromes & 95 & 94 & 98.9 & 1156 & 365 & 31.6 & 48 & 51.1 & 36 & 38.3 & 12.3 & 3.9 & 24.1 & 7.6 & 7 & 7.4 \\
\hline $\begin{array}{l}\text { increased } \\
\text { expression }\end{array}$ & 93 & 85 & 91.4 & 1518 & 388 & 25.6 & 43 & 50.6 & 33 & 38.8 & 17.9 & 4.6 & 35.3 & 9.0 & 6 & 7.1 \\
\hline
\end{tabular}


Table 3 Orthologous genes in the KN400 and PCA strains that have the highest level of protein-changing single nucleotide polymorphisms per kb (proteins of unknown function not shown)

\begin{tabular}{|c|c|c|c|c|}
\hline Gene & Annotation & PCA ortholog & $\begin{array}{l}\text { Non-synonymous SNP } \\
\text { per } 1000 \text { bases }\end{array}$ & Total SNP \\
\hline KN400_0176 & quinoline oxidoreductase, small subunit protein & GSU0200 & 17.0 & 25 \\
\hline KN400_0177 & quinoline oxidoreductase, large subunit protein & GSU0201 & 21.6 & 174 \\
\hline KN400_0192 & FMN-cofactor binding protein & GSU0217 & 12.4 & 20 \\
\hline KN400_0193 & cytochrome c oxidase synthesis (SCO) factor & GSU0218 & 14.4 & 32 \\
\hline KN400_0196 & cytochrome c oxidase, subunit IV & GSU0221 & 13.8 & 11 \\
\hline KN400_0197 & cytochrome c oxidase, subunit II & GSU0222 & 12.0 & 44 \\
\hline KN400_0198 & cytochrome c oxidase assembly factor & GSU0223 & 18.5 & 43 \\
\hline KN400_0202 & DNA methyltransferase & GSU0227 & 19.6 & 53 \\
\hline KN400_0225 & sensor histidine kinase & GSU0253 & 20.1 & 118 \\
\hline KN400_0281 & DnaJ domain protein & GSU0313 & 15.6 & 21 \\
\hline KN400_0418 & ribonuclease D & GSU0443 & 20.1 & 64 \\
\hline KN400_0545 & DNA-3-methyladenine glycosylase I & GSU0567 & 19.1 & 28 \\
\hline KN400_0547 & nicotinamidase-related cysteine hydrolase & GSU0569 & 21.9 & 29 \\
\hline KN400_0597 & cytochrome c (OmcE) & GSU0618 & 25.8 & 44 \\
\hline KN400_0681 & cytochrome c biogenesis, ResB & GSU0704 & 12.8 & 36 \\
\hline KN400_0803 & sensor histidine kinase & GSU0822 & 13.7 & 68 \\
\hline KN400_0811 & efflux pump, RND family, membrane fusion protein & GSU0829 & 40.2 & 116 \\
\hline KN400_0818 & response regulator & GSU0837 & 12.2 & 8 \\
\hline KN400_0880 & 3-oxoalanine-generating family protein & GSU0897 & 17.1 & 55 \\
\hline KN400_0883 & SAM-dependent methyltransferase & GSU0900 & 19.1 & 40 \\
\hline KN400_0885 & response receiver & GSU3516 & 12.8 & 17 \\
\hline KN400_0887 & sensor histidine kinase & GSU3518 & 16.8 & 68 \\
\hline KN400_0892 & pyranopterin cofactor biosynthesis, MoeB & GSU0907 & 34.3 & 44 \\
\hline KN400_0893 & pyranopterin cofactor biosynthesis, MoaD & GSU0908 & 32.0 & 22 \\
\hline KN400_0899 & ATP-dependent RNA helicase RhIE & GSU0914 & 17.9 & 105 \\
\hline KN400_0908 & ABC transporter, ATP-binding protein & GSU0922 & 12.4 & 75 \\
\hline KN400_0914 & zinc-dependent peptidase, M16 family & GSU0928 & 16.0 & 77 \\
\hline KN400_0950 & protease & GSU0969 & 16.3 & 73 \\
\hline KN400_0995 & OmpA family outer membrane lipoprotein & GSU1013 & 15.0 & 37 \\
\hline KN400_0996 & smr domain protein & GSU1014 & 26.4 & 40 \\
\hline KN400_1013 & methyl-accepting chemotaxis sensory transducer & GSU3523 & 19.6 & 153 \\
\hline KN400_1014 & methyl-accepting chemotaxis sensory transducer & GSU1035 & 15.2 & 107 \\
\hline KN400_1117 & methyl-accepting chemotaxis sensory transducer & GSU1141 & 14.5 & 72 \\
\hline KN400_1307 & cytochrome c & GSU1334 & 16.7 & 81 \\
\hline KN400_1319 & sulfate $A B C$ transporter, periplasmic sulfate-binding & GSU1346 & 20.7 & 58 \\
\hline KN400_1320 & sulfate $A B C$ transporter, membrane protein Cys $U$ & GSU1347 & 16.8 & 31 \\
\hline KN400_1510 & transcriptional regulator, MarR family & GSU1483 & 49.0 & 59 \\
\hline KN400_1862 & membrane-associated phosphatase, PAP2_like_5 family & GSU1840 & 12.2 & 15 \\
\hline KN400_1865 & RNA exonuclease & GSU1843 & 18.2 & 58 \\
\hline KN400_1866 & IPT/TIG domain protein & GSU1844 & 12.5 & 107 \\
\hline KN400_1884 & IPT/TIG domain protein & GSU1858 & 25.1 & 173 \\
\hline KN400_2002 & exopolysaccharide synthesis exosortase & GSU1979 & 12.6 & 38 \\
\hline KN400_2006 & protein tyrosine kinase & GSU1983 & 14.0 & 27 \\
\hline
\end{tabular}


Table 3 Orthologous genes in the KN400 and PCA strains that have the highest level of protein-changing single nucleotide polymorphisms per $\mathbf{k b}$ (proteins of unknown function not shown) (Continued)

\begin{tabular}{|c|c|c|c|c|}
\hline KN400_2106 & D-glycero-D-mannoheptose-1,7-bisphosphate phosphatase & GSU2084 & 12.2 & 20 \\
\hline KN400_2110 & glycosyltransferase, group 2 family protein & GSU2088 & 57.0 & 139 \\
\hline KN400_2282 & trehalose-6-phosphatase & GSU2336 & 26.6 & 41 \\
\hline KN400_2284 & sodium/proton antiporter complex Mrp, protein G & GSU2338 & 43.8 & 52 \\
\hline KN400_2286 & sodium/proton antiporter complex Mrp, protein E & GSU2340 & 40.2 & 62 \\
\hline KN400_2287 & sodium/proton antiporter complex Mrp, protein D & GSU2341 & 16.5 & 106 \\
\hline KN400_2288 & sodium/proton antiporter complex Mrp, protein C & GSU2342 & 46.6 & 18 \\
\hline KN400_2382 & ATP-dependent protease, putative & GSU2433 & 12.2 & 77 \\
\hline KN400_2399 & peptide methionine sulfoxide reductase & GSU2451 & 14.5 & 19 \\
\hline KN400_2420 & TPR domain protein & GSU2476 & 17.6 & 74 \\
\hline KN400_2445 & YVTN family beta-propeller domain protein & GSU3586 & 16.6 & 59 \\
\hline KN400_2449 & cytochrome c (OmcS) & GSU2504 & 15.4 & 51 \\
\hline KN400_2452 & sensor histidine kinase & GSU2507 & 13.9 & 70 \\
\hline KN400_2454 & TPR domain protein & GSU2508 & 24.5 & 96 \\
\hline KN400_2457 & sensor diguanylate cyclase/phosphoesterase & GSU2511 & 17.6 & 142 \\
\hline KN400_2460 & cytochrome c & GSU2513 & 31.8 & 27 \\
\hline KN400_2624 & 2-dehydropantoate 2-reductase & GSU2683 & 38.5 & 104 \\
\hline KN400_2644 & transcriptional regulator, TetR family & GSU2698 & 13.9 & 33 \\
\hline KN400_2649 & molybdopterin-molybdenum ligase & GSU2703 & 12.3 & 59 \\
\hline KN400_2658 & fibronectin type III domain protein & GSU2715 & 48.7 & 294 \\
\hline KN400_2660 & hydrogenase, bidirectional NAD-reducing, protease & GSU2717 & 30.8 & 35 \\
\hline KN400_2668 & cytochrome c & GSU2725 & 25.4 & 31 \\
\hline KN400_2716 & transcriptional regulator, MerR family & GSU2779 & 18.0 & 30 \\
\hline KN400_2747 & transcriptional regulator, Fur family & GSU2809 & 30.6 & 35 \\
\hline KN400_2750 & glutaredoxin family protein & GSU2812 & 89.8 & 60 \\
\hline KN400_2997 & NADPH ferredoxin oxidoreductase (FNOR) beta subunit & GSU3058 & 15.6 & 32 \\
\hline KN400_3000 & squalene cyclase domain protein & GSU3061 & 12.3 & 107 \\
\hline KN400_3006 & UDP-N-acetylenolpyruvylglucosamine reductase & GSU3067 & 21.1 & 58 \\
\hline KN400_3214 & cytochrome c & GSU3274 & 28.8 & 32 \\
\hline KN400_3301 & sensor histidine kinase & GSU3357 & 22.2 & 146 \\
\hline KN400_3348 & OmpJ-related porin & GSU3403 & 29.9 & 97 \\
\hline KN400_3368 & dihydrolipoamide dehydrogenase-related protein & GSU3424 & 16.4 & 86 \\
\hline
\end{tabular}

synthesis [1,15]. The electrons that remain from this process are transferred out of the cell to Fe(III) or to electrodes.

In total, 65 genes in strain PCA encode the proteins involved in acetate oxidation, and the KN400 strain has orthologs to each of these (Additional file 1: Table S10). Ten of the 65 contain a protein sequence change, with fewer per gene than the genome as a whole (0.4 versus 1.6 non-synonymous SNP per gene) (Table 2). None are highly mutated.

Separately from energy generation, a portion of acetate is shunted to a different pathway and used as the sole source for biomass synthesis via the gluconeogenic and fatty acid pathways $[15,16]$. 20 genes are involved in this other fate of acetate and the KN400 strain has orthologs to each of these (Additional file 1: Table S10). However, two reactions from this pathway show higher sequence changes between the strains - phosphate acetyltransferase and acetate kinase (PAT - GSU2706, AK GSU2707). In KN400 the acetyltransferase has 38 SNP (8 non-synonymous) and the kinase has 45 SNP (7 nonsynonymous), with a 27-fold higher non-synonymous $\mathrm{SNP} / \mathrm{kb}$ ratio than the other enzymes of central energy metabolism (Table 2, Additional file 1: Table S10).

The sequence differences in PAT and AK stand out as the most pronounced in the otherwise very well- 
conserved enzymes of central energy metabolism. It has previously been shown that strain PCA cannot grow on acetate alone if either PAT or AK is knocked out [16]. This phenotype arises because the CoA-transferase that activates acetate for oxidation in the TCA cycle requires CoA derived from the TCA cycle itself. Therefore, additional pathways are needed to produce acetyl-CoA for biosynthetic pathways. With acetate as the sole growth substrate, this anaplerotic function is performed by AK and PAT.

Differences in these two enzymes could have a substantial effect on the flux between acetate oxidation and reduction, and thereby on electron transport rates out of the cell and on biomass production. A lower flux through AK/PAT relative to the TCA cycle would translate to a decreased biomass yield per molecule of acetate oxidized and a higher ratio of electrons transferred to the electrode per cell - the phenotype seen in the KN400 strain [5].

\section{Sequence differences in extra-cytoplasmic electron transfer proteins}

G. sulfurreducens grows by using Fe(III) oxide or energy-harvesting electrodes as the terminal electron acceptor [2,17]. Cytochromes, pili, and exopolysaccharides have all been shown to be important for growth using these extracellular electron acceptors [1].

For both the PCA and KN400 strains, the whole proteomes were scanned for the heme-binding motif of $c$ type cytochromes [18] (Additional file 1: Table S11). In each strain, 135 genes encode proteins with this C-X-X$\mathrm{C}-\mathrm{H}$ motif (Additional file 1: Table S11). Since this definition of cytochrome is minimal, proteins were excluded as cytochromes if they had a predicted function or cellular localization that indicated that they were not involved in electron transport outside the cell; most were proteins with iron-sulfur-binding domains (Additional file 1: Table S11).

In total, 107 genes in the PCA and 106 in the KN400 strain were predicted to encode $c$-type cytochromes (Additional file 1: Table S11). Only one of the PCA cytochromes lacked an ortholog in KN400: GSU2515, a monoheme cytochrome that has not been shown to be involved in electron transport. Fifty-four of the $106 \mathrm{c}$ type cytochromes contain at least one SNP in KN400 relative to PCA (51\%), compared to $36 \%$ of genes in the whole genome (Table 2).

There were more than two-fold more SNP per cytochrome compared to the genome as a whole: 12.3 vs 5.6 $\mathrm{SNP} /$ gene, and almost twice as many of the encoded proteins were heavily mutated: $7.4 \%$ vs $3.6 \%$ (Table 2 ). However, all 106 of the orthologous cytochromes had the same number of predicted heme-binding sites, with up to 27 motifs in a single protein (Additional file 1:
Table S11). So, while the cytochromes have more than the average number of changes to nucleotide and protein sequences, these changes do not result in a change to the number of hemes predicted to be bound to each cytochrome. This indicates that the proteins' electron carrying capacity may still function, though perhaps with a changed redox potential due to structural differences [19].

Most of the cytochromes previously shown to be required for growth with $\mathrm{Fe}(\mathrm{III})$ or for optimal current production [1] are identical in KN400 and PCA, including PpcA, MacA, OmcB, OmcC, OmcF, and OmcZ (Additional file 1: Table S11).

However, two cytochromes are among the most heavily mutated genes in the genomes and are required for extracellular electron transfer - OmcE and OmcS (GSU0618, GSU2504) (Table 3, Additional file 1: Table $\mathrm{S} 11$ ). The omcS gene is found in a region (27435002775500 in PCA) that has one of the highest SNP rates in the genome: $36 \mathrm{SNP} / \mathrm{kb}$. Of the 22 genes encoded, 8 are heavily mutated, one is frameshifted, and three lack orthologs in the KN400 strain (Additional file 1: Table S2). This region also encodes six other c-type cytochromes: GSU2494, GSU2495, GSU2501, GSU2503 (omcT), GSU2513 and GSU2515. Finding significant changes to OmcS in particular is especially relevant in the KN400 strain because this cytochrome has been shown to be localized outside of the cell along the length of the pili [20] where it may facilitate electron transfer from pili to the terminal electron acceptor [6,21]. Changes to the electron-carrying protein at this key position for electrical contact could have a substantial effect on phenotype.

Pili are also required for the reduction of extracellular electron acceptors by G. sulfurreducens $[21,22]$. They are believed to provide a conduit for electron transfer through biofilms and to the cytochromes responsible for Fe(III) oxide reduction [6]. There are 24 genes involved in biogenesis and assembly of pili (GSU0146, GSU0230, GSU0436, GSU1063-GSU1066, GSU1491-GSU1496, GSU2028-GSU2038, GSU3548, GSU2043). All 24 genes have orthologs in the KN400 strain (Additional file 1: Table S1), and they are all well conserved - 20 of the genes are identical at the nucleotide level between the strains, and only one has a single non-synonymous mutation, a PilT homolog (GSU0436).

Extracellular polysaccharides are also required for electrode reduction; they are involved in anchoring the $c$-type cytochromes that provide the electrical conduit between the cell and the electrode surface [23]. Five of the genes in the extracellular anchoring polysaccharide gene cluster (GSU1498 to GSU1508) have nonsynonymous SNP (Additional file 1: Table S2), including one in the an $\mathrm{ABC}$ transporter ATPase subunit required for polysaccharide production [23]. 
Finally, OmpB and $\mathrm{OmpC}$ are putative copper-binding oxidoreductases required for insoluble Fe(III) reduction in G. sulfurreducens [24,25]. The ompB gene (GSU1394) is identical between the two strains, and ompC (GSU2657) has a single synonymous mutation.

Thus between the KN400 and the PCA strains there is both conservation and divergence among the extracytoplasmic proteins involved in transferring electrons out of the cell. Most previously known to be required in vivo did not have large sequence differences, including six cytochromes, two copper proteins, and the pilin. However, cytochromes considered as a class were much more likely to contain non-synonymous SNP, and two important cytochromes, OmcS and OmcE, have especially large differences. Notably though, not a single heme-binding site was lost due to the changes. These data support previous analyses showing that a diversity of cytochromes are characteristic of Geobacter species, but individual cytochromes tend to be poorly conserved [26]. This kind of cytochrome diversity and adaptability may be especially important for the use of terminal electron acceptors with a wide variety of redox potentials.

\section{Sequence differences in the genes with increased expression during growth on an electrode}

Two previous studies have analyzed changes in gene expression in the PCA strain during growth on an energyharvesting electrode. Given the improvements in electron transfer to electrodes in the KN400 strain relative to PCA, any sequence changes in these genes are of particular interest. The first study looked at gene expression in the early stages of anode biofilm formation, and showed that 93 genes had an increase in transcript abundance compared to growth by Fe(III) reduction [27]. The second looked at expression changes in established, high-current-density biofilms, and showed that 13 genes had an increase in transcript abundance compared to growth with fumarate as an electron acceptor [22].

Only one of the 13 genes with increased expression on the high-current electrode had substantial changes between the KN400 and the PCA strain. OmpJ is an outermembrane channel protein known to influence the quantity and localization of cytochromes in G. sulfurreducens [28], so changes to its sequence could influence electron transfer very broadly. OmpJ (GSU3403) has 3fold higher expression during growth on the electrode, and it was among the most highly mutated genes between the two strains, with 30 non-synonymous changes per kb (Additional file 1: Table S9).

Twenty-four genes have increased expression during early-stage growth on the electrode and also had either no ortholog or large sequence differences in the KN400 strain (Table 4). The omcS cytochrome gene is the most highly up-regulated of all genes and it was among the proteins with the largest sequence difference between the KN400 and PCA strains (discussed above). A third copper-binding oxidoreductase has increased expression during growth on the electrode [27], and the cluster encoding this multicopper oxidase, as well as a cytochrome $d$ and two copper chaperone proteins (GSU1251GSU1257) had large sequence differences (Additional file 1: Table S2). Unlike OmpB and OmpC (mentioned above), the role of these proteins in electron transfer has not been studied, though interestingly the most similar complex is found in the Fe(II)-oxidizing Leptothrix species [29].

In addition to these copper proteins, a transcriptional regulator (GSU2779) with homology to CueR, a copperresponsive transcriptional activator [30], has a four-fold increase in expression on the electrode and was heavily mutated in the KN400 strain (Table 4). The CueR protein is broadly involved in metal homeostasis, and three general metal efflux pumps also have increased expression on the electrode and sequence changes in KN400. The first pump (GSU2135-GSU2137) was one of the few proteins in PCA that lacked orthologs in KN400 (Table 4), and two others have non-synonymous SNPs (GSU0829-GSU0830 and GSU1338-GSU1341).

Immediately downstream of one of the metal pumps, a fourth important transporter has large differences between the KN400 and PCA strains: the only sulfate transporter in the genome (GSU1350-GSU1352) was heavily mutated in KN400 (Table 3). This is upstream of three additional genes for sulfur metabolism: a sulfite reductase, a sulfur carrier protein, and a thiocarboxylate synthase (GSU1350-GSU1352), which are among the few in PCA that lack orthologs entirely in KN400 (Additional file 1: Table S5). These changes indicate that KN400 may have a significant difference in its usage of sulfur, copper, and perhaps other metals, which could have far-reaching impact on the types of redox proteins active in the KN400 strain.

\section{Conclusions}

The KN400 strain of G. sulfurreducens was isolated from a fuel cell that was run for several months poised at increasingly lower potentials. Its $16 \mathrm{~S}$ rRNA genes are identical to those in the well-studied PCA strain, but the quantity of nucleotide polymorphisms and their strong enrichment at silent sites, as well as the diversity and distribution of genes that lack orthologs between the genomes all suggest the strains have been subject to substantial selective pressure since their divergence. Further study of strain variation in G. sulfurreducens - these two are the only strains that have been sequenced - and the analysis of more closely related genomes would help to 
Table 4 Genes in strain PCA that have increased expression during growth with an electrode as the electron acceptor and that lack orthologs or have a high level of protein-changing single nucleotide polymorphisms per kb

\begin{tabular}{|c|c|c|c|c|}
\hline PCA gene & Annotation & KN400 ortholog & $\begin{array}{l}\text { Non-synonymous SNPs } \\
\text { per } 1000 \text { bases }\end{array}$ & $\begin{array}{l}\text { electrode increase } \\
\text { expression (fold-change) }\end{array}$ \\
\hline GSU0062 & TraD protein & none & & 1.34 \\
\hline GSU0618 & cytochrome c (OmcE) & KN400_0597 & 25.8 & 1.98 \\
\hline GSU0829 & efflux pump, membrane fusion protein & KN400_0811 & 40.2 & 1.69 \\
\hline GSU0955 & RNA-directed DNA polymerase & none & & 1.76 \\
\hline GSU1253 & cytochrome d & KN400_1227 & 13.7 & 1.65 \\
\hline GSU1844 & IPT/TIG domain protein & KN400_1866 & 12.5 & 1.55 \\
\hline GSU2113 & transcriptional regulator & none & & 1.4 \\
\hline GSU2129 & conserved hypothetical protein & none & & 1.38 \\
\hline GSU2133 & lipoprotein & none & & 1.62 \\
\hline GSU2135 & metal efflux pump, inner membrane protein & none & & 1.73 \\
\hline GSU2136 & metal efflux pump, membrane fusion protein & none & & 1.88 \\
\hline GSU2137 & metal efflux pump, outer membrane protein & none & & 1.94 \\
\hline GSU2139 & transposase & none & & 1.28 \\
\hline GSU2143 & conserved hypothetical protein & none & & 3.82 \\
\hline GSU2471 & RNA-directed DNA polymerase & none & & 1.56 \\
\hline GSU2476 & TPR domain protein & KN400_2420 & 17.6 & 1.49 \\
\hline GSU2497 & lipoprotein & KN400_2442 & 23.8 & 1.32 \\
\hline GSU2504 & cytochrome c (OmcS) & KN400_2449 & 15.4 & 19.46 \\
\hline GSU2507 & sensor histidine kinase & KN400_2452 & 13.9 & 1.41 \\
\hline GSU2508 & TPR domain protein & KN400_2454 & 24.5 & 1.37 \\
\hline GSU2690 & VacJ family lipoprotein & KN400_2637 & 36.6 & 1.35 \\
\hline GSU2773 & conserved domain protein & none & & 1.62 \\
\hline GSU2779 & transcriptional regulator & KN400_2716 & 18.0 & 3.77 \\
\hline GSU3067 & UDP-N-acetylenolpyruvylglucosamine reductase & KN400_3006 & 21.1 & 1.32 \\
\hline GSU3403* & OmpJ porin & KN400_3348 & 29.9 & 2.76 \\
\hline
\end{tabular}

reconstruct a detailed evolutionary history, particularly of the genomic mobility seen in this species.

The KN400 strain has a number of favorable characteristics that make it the preferred strain to grow in a microbial fuel cell. The first is speed of electron transfer: KN400 oxidizes the donor and transfers the resulting electrons to the electrode faster than PCA [5]. Analysis of the differences between the two genomes suggests (and eliminates) several explanations for this phenotype. KN400 does not contain additional genes that PCA lacks which are predicted to be involved in donor oxidation, nor does it contain any large sequence changes to the enzymes for acetate oxidation via the TCA cycle. However, there are significant changes to two anaplerotic enzymes that could shift the carbon flux in the KN400 strain from biomass production towards more rapid oxidation of acetyl-CoA. If these two enzymes have lower activity in KN400, the TCA cycle may complete full turns more often, and this would increase the fraction of acetate that is oxidized for respiration.
Interestingly, the increased respiration rate does not lead to increased cell growth in the KN400 strain [5], indicating that there may be important changes in ATP synthesis or availability. Previously, a PCA strain engineered with an unproductive ATP sink exhibited a similar phenotype [31]. In the KN400 genome, a very broad range of ATP-dependent enzymes were more likely to have sequence changes, and the phosphate sensor, transporter and several phosphate regulators were all also changed. Thus, the phosphate levels, the ATP:ADP ratio, and the energy state of the cell may be different in the KN400 strain relative to the PCA strain, which could result in broad metabolic differences.

The second favorable characteristic of KN400 when grown in a microbial fuel cell is its highly conductive biofilms [6] from which low-potential electrons can be harvested. Analysis of the differences between the two genomes also suggests (and eliminates) factors that may contribute to this phenotype. Though pili are the conductive material in KN400 biofilms, there are no 
differences in the pilin subunit, biogenesis genes, nor the PilR transcriptional regulator between the strains. However the cell-electrode connection is also mediated by $c$ type cytochromes, and there are substantial differences between the strains in these proteins. The sequences of both cytochromes and of the channel proteins that affect their localization have substantial changes, most notably in the OmcS cytochrome that is physically associated with the pili. In addition, there are changes to several clusters of exopolysaccharide biosynthesis genes in KN400 which may further affect cytochrome localization and general conductivity. Excellent conservation of heme-binding sites despite sequence changes indicates that cytochrome redox potential changes also warrant further investigation in the KN400 strain. Finally, sensing and response to global redox potential and metal homeostasis may have significant differences in KN400 due to changes in proteins involved in the transport and metabolism of copper, of sulfur, and of metals generally. These types of changes would have a broad impact on electron transport in the species.

\section{Methods}

\section{Genome reannotation}

In regions of nucleotide sequence conservation where an ORF was predicted in only one of the genomes, ORFs were added if the gene products had predicted functions; if they were conserved in genomes other than G. sulfurreducens; if they had multiple homologs in G. sulfurreducens; or if they had plausible predicted ribosome-binding sites. ORFs were removed if they overlapped other features such as ORFs, tRNAs, CRISPRs (clustered regularly interspaced short palindromic repeats), riboswitches, or strong hairpins. In total 162 ORFs or pseudogenes were added to the genome of strain PCA, and 158 ORFs or pseudogenes were removed (from the original 3469 ORFs and pseudogenes). In total 108 ORFs or pseudogenes were added to the genome of strain KN400 and 177 were removed (from the original 3421 ORFs and pseudogenes) (Additional file 1: Table S1 and Additional file 1: Table S2).

Discrepancies in start coordinates between homologous genes in strain KN400 and strain PCA were resolved by identifying plausible ribosome-binding sites. In cases where no homologs were detected in any other species and both predicted starts possessed ribosomebinding sites, the protein sequences were examined for the presence of a short N-terminal hydrophobic segment indicating a putative signal peptide. Start sites that placed signal peptides nearer to the $\mathrm{N}$-terminus were preferred. In the absence of a signal peptide, the start site resulting in a longer ORF was preferred. Finally, in a few cases the discrepancies in start sites were due to a frameshift that was present in the ortholog in one of the strains but absent in the other (Additional file 1: Table S1 and Additional file 1: Table S2). Stop coordinates were adjusted only if there were predicted selenocysteine codons, frameshifts, or nonsense codons interrupting an alignment of protein sequences. In total 403 start sites were changed in the strain PCA genome, and 435 start sites were changed in the strain KN400 genome. Six stop sites were changed in the strain PCA genome, and 16 stop sites were changed in the strain KN400 genome.

To determine functional annotation and most closely related species, all ORFs in both genomes were compared to the National Center for Biotechnology Information Reference Sequence Database [9], the Conserved Domain Database [32], MicrobesOnline comparative genomics databases [33], and the G. sulfurreducens metabolic model [15].

\section{Ortholog prediction}

The PCA and KN400 genome sequences were aligned using progressive Mauve version 2.3.0 with a match seed weight of 15 and the HOXD scoring matrix [34] and manual refinement, and orthologs were predicted based on this alignment. Orthologs were also identified without considering genome position by identifying reciprocal best BLAST matches in all-against-all proteome comparisons [35]. Differences in these methods were resolved as described in the text. Genome figures were made using Circos [36] and Mauve.

\section{Polymorphism detection}

Custom scripts (Additional file 3) were written to identify differences between the sequences of the strains, including single nucleotide polymorphisms and insertions and deletions, and to calculate protein percent identity, using the Mauve alignment as the input. Sequence differences in the coding regions were determined to have synonymous or non-synonymous effects using the standard bacterial genetic code. Where there was more than one sequence change in the triplet, each was considered independently.

\section{Functional enrichment}

Gene ontology functional enrichment was done using DAVID software [37]. The background gene set was all genes in the G. sulfurreducens PCA genome. All test sets had at least 100 genes. Enrichment was tested for the functional categories derived from the gene ontology database [38], the COG database [39], the Protein Information Resource database [40], and the InterPro database [41]. Enrichment in function in the test set of genes versus the whole-genome background was determined with a modified Fisher's exact test (EASE score) [37], with p-value cut-offs at either 0.05 or 0.01 for significance. 


\section{Additional files}

Additional file 1: Table S1. - KN400 genome; Table S2. - PCA genome; Table S3. - KN400 genes that lack an ortholog in the PCA strain; Table S4. - regions in the KN400 genome that lack an ortholog in the PCA strain; Table S5. - PCA genes that lack an ortholog in the KN400 strain; Table S6. - Gene ontology enrichment analysis; Table S7. - Regions in the PCA genome that lack an ortholog in the KN400 strain; Table S8. - Single nucleotide polymorphisms across the genome; Table S9. - Heavily mutated proteins; Table S10. - Polymorphisms in the genes of central metabolism; Table S11. - Polymorphisms in the cytochromes.

Additional file 2: Figure S1. Alignment of the genomes of G. sulfurreducens strain PCA and strain KN400. Figure S2. A large region of low similarity between the KN400 and PCA genomes.

\section{Additional file 3: Scripts for polymorphism detection.}

\section{Competing interests}

The authors declare that they have no competing interests.

\section{Authors' contributions}

JB designed the comparative experiments, analyzed the polymorphism data and wrote the manuscript; MA re-annotated the genomes and helped write the manuscript; NY wrote the analysis scripts and helped with the comparative analysis; DL helped write the manuscript. All authors read and approved the final manuscript.

\section{Acknowledgement}

This research was supported by the Office of Science (BER), U. S. Department of Energy, Cooperative Agreement No. DE-FC02-02ER63446.

Received: 24 February 2012 Accepted: 6 August 2012

Published: 12 September 2012

\section{References}

1. Lovley DR, Ueki T, Zhang T, Malvankar NS, Shrestha PM, Flanagan KA, Aklujkar M, Butler JE, Giloteaux L, Rotaru AE, Holmes DE, Franks AE, Orellana R, Risso C, Nevin KP: Geobacter: the microbe electric's physiology, ecology, and practical applications. Adv Microb Physiol 2011, 59:1-100.

2. Bond DR, Lovley DR: Electricity production by Geobacter sulfurreducens attached to electrodes. Appl Environ Microbiol 2003, 69(3):1548-1555.

3. Franks AE, Nevin KP: Microbial fuel cells, a current review. Energies 2010, 3:899-919.

4. Nevin KP, Richter $H$, Covalla SF, Johnson JP, Woodard TL, Orloff AL, Jia H, Zhang M, Lovley DR: Power output and columbic efficiencies from biofilms of Geobacter sulfurreducens comparable to mixed community microbial fuel cells. Environ Microbiol 2008, 10(10):2505-2514.

5. Yi H, Nevin KP, Kim BC, Franks AE, Klimes A, Tender LM, Lovley DR: Selection of a variant of Geobacter sulfurreducens with enhanced capacity for current production in microbial fuel cells. Biosens Bioelectron 2009, 24(12):3498-3503.

6. Malvankar NS, Vargas M, Nevin KP, Franks AE, Leang C, Kim BC, Inoue K, Mester T, Covalla SF, Johnson JP, Rotello VM, Tuominen MT, Lovley DR: Tunable metallic-like conductivity in microbial nanowire networks. Nat Nanotechnol 2011, 6(9):573-579.

7. Nagarajan H, Butler JE, Klimes A, Qiu Y, Zengler K, Ward J, Young ND, Methe BA, Palsson BO, Lovley DR, Barrett CL: De novo assembly of the complete genome of an enhanced electricity-producing variant of Geobacter sulfurreducens using only short reads. PLoS One 2010, 5(6):e10922.

8. Methe BA, Nelson KE, Eisen JA, Paulsen IT, Nelson W, Heidelberg JF, Wu D, Wu M, Ward N, Beanan MJ, Dodson RJ, Madupu R, Brinkac LM, Daugherty SC, DeBoy RT, Durkin AS, Gwinn M, Kolonay JF, Sullivan SA, Haft DH, Selengut J, Davidsen TM, Zafar N, White O, Tran B, Romero C, Forberger HA, Weidman J, Khouri H, Feldblyum TV, Utterback TR, Van Aken SE, Lovley DR, Fraser CM: Genome of Geobacter sulfurreducens: metal reduction in subsurface environments. Science 2003, 302(5652):1967-1969.

9. Pruitt KD, Tatusova T, Maglott DR: NCBI reference sequences (RefSeq): a curated non-redundant sequence database of genomes, transcripts and proteins. Nucleic Acids Res 2007, 35(Database issue):D61-D65.
10. Wozniak RA, Waldor MK: Integrative and conjugative elements: mosaic mobile genetic elements enabling dynamic lateral gene flow. Nat Rev Microbiol 2010, 8(8):552-563.

11. Chelikani P, Fita I, Loewen PC: Diversity of structures and properties among catalases. Cell Mol Life Sci 2004, 61(2):192-208.

12. Imlay JA: Pathways of oxidative damage. Annu Rev Microbiol 2003, 57:395-418.

13. Aklujkar M, Lovley DR: Interference with histidyl-tRNA synthetase by a CRISPR spacer sequence as a factor in the evolution of Pelobacter carbinolicus. BMC Evol Biol 2010, 10(1):230.

14. Terns MP, Terns RM: CRISPR-based adaptive immune systems. Curr Opin Microbiol 2011, 14(3):321-327.

15. Mahadevan R, Bond DR, Butler JE, Esteve-Nunez A, Coppi MV, Palsson BO, Schilling $\mathrm{CH}$, Lovley DR: Characterization of metabolism in the Fe(III)reducing organism Geobacter sulfurreducens by constraint-based modeling. Appl Environ Microbiol 2006, 72(2):1558-1568.

16. Segura D, Mahadevan R, Juarez K, Lovley DR: Computational and experimental analysis of redundancy in the central metabolism of Geobacter sulfurreducens. PLoS Comput Biol 2008, 4(2):e36.

17. Caccavo F Jr, Lonergan DJ, Lovley DR, Davis M, Stolz JF, Mclnerney MJ: Geobacter sulfurreducens sp. nov., a hydrogen- and acetate-oxidizing dissimilatory metal-reducing microorganism. Appl Environ Microbiol 1994 60(10):3752-3759.

18. Simon J, Hederstedt L: Composition and function of cytochrome C biogenesis System II. FEBS J 2011, 278(22):4179-4188.

19. Morgado L, Fernandes AP, Londer YY, Pokkuluri PR, Schiffer M, Salgueiro CA: Thermodynamic characterization of the redox centres in a representative domain of a novel c-type multihaem cytochrome. Biochem J 2009, 420(3):485-492.

20. Leang C, Qian X, Mester T, Lovley DR: Alignment of the c-type cytochrome OmcS along pili of Geobacter sulfurreducens. Appl Environ Microbiol 2010, 76(12):4080-4084.

21. Reguera G, McCarthy KD, Mehta T, Nicoll JS, Tuominen MT, Lovley DR: Extracellular electron transfer via microbial nanowires. Nature 2005, 435(7045):1098-1101.

22. Nevin KP, Kim BC, Glaven RH, Johnson JP, Woodard TL, Methe BA, Didonato RJ, Covalla SF, Franks AE, Liu A, Lovley DR: Anode biofilm transcriptomics reveals outer surface components essential for high density current production in Geobacter sulfurreducens fuel cells. PLoS One 2009, 4(5):e5628.

23. Rollefson JB, Stephen CS, Tien M, Bond DR: Identification of an extracellular polysaccharide network essential for cytochrome anchoring and biofilm formation in Geobacter sulfurreducens. J Bacteriol 2011, 193(5):1023-1033.

24. Mehta T, Childers SE, Glaven R, Lovley DR, Mester T: A putative multicopper protein secreted by an atypical type II secretion system involved in the reduction of insoluble electron acceptors in Geobacter sulfurreducens. Microbiology 2006, 152(Pt 8):2257-2264.

25. Holmes DE, Mester T, O'Neil RA, Perpetua LA, Larrahondo MJ, Glaven R, Sharma ML, Ward JE, Nevin KP, Lovley DR: Genes for two multicopper proteins required for $\mathrm{Fe}$ (III) oxide reduction in Geobacter sulfurreducens have different expression patterns both in the subsurface and on energy-harvesting electrodes. Microbiology 2008, 154(Pt 5):1422-1435.

26. Butler JE, Young ND, Lovley DR: Evolution of electron transfer out of the cell: comparative genomics of six Geobacter genomes. BMC Genomics 2010, 11:40

27. Holmes DE, Chaudhuri SK, Nevin KP, Mehta T, Methe BA, Liu A, Ward JE, Woodard TL, Webster J, Lovley DR: Microarray and genetic analysis of electron transfer to electrodes in Geobacter sulfurreducens. Environ Microbiol 2006, 8(10):1805-1815.

28. Afkar E, Reguera G, Schiffer M, Lovley DR: A novel Geobacteraceae-specific outer membrane protein $\mathrm{J}(\mathrm{OmpJ})$ is essential for electron transport to $\mathrm{Fe}(\mathrm{III})$ and Mn(IV) oxides in Geobacter sulfurreducens. BMC Microbiol 2005, 5:41.

29. Spring S, Kampfer P, Ludwig W, Schleifer KH: Polyphasic characterization of the genus Leptothrix: New descriptions of Leptothrix mobilis sp. nov. and Leptothrix discophora sp. nov. nom. rev. and emended description of Leptothrix cholodnii emend. Syst Appl Microbiol 1996, 19(4):634-643.

30. Stoyanov JV, Hobman JL, Brown NL: CueR (Ybbl) of Escherichia coli is a MerR family regulator controlling expression of the copper exporter CopA. Mol Microbiol 2001, 39(2):502-511. 
31. Izallalen M, Mahadevan R, Burgard A, Postier B, Didonato $R \mathrm{Jr}$, Sun J, Schilling CH, Lovley DR: Geobacter sulfurreducens strain engineered for increased rates of respiration. Metab Eng 2008, 10(5):267-275.

32. Marchler-Bauer A, Anderson JB, Chitsaz F, Derbyshire MK, DeWeese-Scott C Fong JH, Geer LY, Geer RC, Gonzales NR, Gwadz M, He S, Hurwitz DI, Jackson JD, Ke Z, Lanczycki CJ, Liebert CA, Liu C, Lu F, Lu S, Marchler GH, Mullokandov M, Song JS, Tasneem A, Thanki N, Yamashita RA, Zhang D, Zhang N, Bryant SH: CDD: specific functional annotation with the Conserved Domain Database. Nucleic Acids Res 2009, 37(Database issue): D205-D210.

33. Dehal PS, Joachimiak MP, Price MN, Bates JT, Baumohl JK, Chivian D, Friedland GD, Huang KH, Keller K, Novichkov PS, Dubchak IL, Alm EJ, Arkin AP: MicrobesOnline: an integrated portal for comparative and functional genomics. Nucleic Acids Res 2010, 38(Database issue):D396-D400.

34. Darling AC, Mau B, Blattner FR, Perna NT: Mauve: multiple alignment of conserved genomic sequence with rearrangements. Genome Res 2004, 14(7):1394-1403.

35. Altschul SF, Madden TL, Schaffer AA, Zhang J, Zhang Z, Miller W, Lipman DJ: Gapped BLAST and PSI-BLAST: a new generation of protein database search programs. Nucleic Acids Res 1997, 25(17):3389-3402.

36. Krzywinski M, Schein J, Birol I, Connors J, Gascoyne R, Horsman D, Jones SJ, Marra MA: Circos: an information aesthetic for comparative genomics. Genome Res 2009, 19(9):1639-1645.

37. da Huang W, Sherman BT, Lempicki RA: Systematic and integrative analysis of large gene lists using DAVID bioinformatics resources. Nat Protoc 2009, 4(1):44-57.

38. Ashburner M, Ball CA, Blake JA, Botstein D, Butler $\mathrm{H}$, Cherry JM, Davis AP, Dolinski K, Dwight SS, Eppig JT, Harris MA, Hill DP, Issel-Tarver L, Kasarskis A, Lewis S, Matese JC, Richardson JE, Ringwald M, Rubin GM, Sherlock G: Gene ontology: tool for the unification of biology. The Gene Ontology Consortium. Nat Genet 2000, 25(1):25-29.

39. Tatusov RL, Koonin EV, Lipman DJ: A genomic perspective on protein families. Science 1997, 278(5338):631-637.

40. Wu CH, Huang H, Nikolskaya A, Hu Z, Barker WC: The iProClass integrated database for protein functional analysis. Comput Biol Chem 2004, 28(1):87-96.

41. Hunter S, Apweiler R, Attwood TK, Bairoch A, Bateman A, Binns D, Bork P Das U, Daugherty L, Duquenne L, Finn RD, Gough J, Haft D, Hulo N, Kahn D, Kelly E, Laugraud A, Letunic I, Lonsdale D, Lopez R, Madera M, Maslen J, McAnulla C, McDowall J, Mistry J, Mitchell A, Mulder N, Natale D, Orengo C, Quinn AF, Selengut JD, Sigrist CJ, Thimma M, Thomas PD, Valentin F, Wilson $\mathrm{D}, \mathrm{Wu} C \mathrm{CH}$, Yeats C: InterPro: the integrative protein signature database. Nucleic Acids Res 2009, 37(Database issue):D211-D215.

doi:10.1186/1471-2164-13-471

Cite this article as: Butler et al:: Comparative genomic analysis of Geobacter sulfurreducens KN400, a strain with enhanced capacity for extracellular electron transfer and electricity production. BMC Genomics 2012 13:471.

\section{Submit your next manuscript to BioMed Central and take full advantage of:}

- Convenient online submission

- Thorough peer review

- No space constraints or color figure charges

- Immediate publication on acceptance

- Inclusion in PubMed, CAS, Scopus and Google Scholar

- Research which is freely available for redistribution 